\title{
Environmental challenge
}

Link to publication record in Manchester Research Explorer

\section{Citation for published version (APA):}

Pfänder, H., Hollingsworth, P., Jimenez, H., \& Won, H. (2009). Environmental challenge: How to close the gap between policy and technology? In 9th AIAA Aviation Technology, Integration and Operations (ATIO) Conference, Aircraft Noise and Emissions Reduction Symposium (ANERS)|AIAA Aviat. Technol., Integr. Oper. (ATIO) Conf., Aircr. Noise Emiss. Reduct. Symp. (ANERS) American Institute of Aeronautics and Astronautics .

\section{Published in:}

9th AIAA Aviation Technology, Integration and Operations (ATIO) Conference, Aircraft Noise and Emissions Reduction Symposium (ANERS)|AIAA Aviat. Technol., Integr. Oper. (ATIO) Conf., Aircr. Noise Emiss. Reduct. Symp. (ANERS)

\section{Citing this paper}

Please note that where the full-text provided on Manchester Research Explorer is the Author Accepted Manuscript or Proof version this may differ from the final Published version. If citing, it is advised that you check and use the publisher's definitive version.

\section{General rights}

Copyright and moral rights for the publications made accessible in the Research Explorer are retained by the authors and/or other copyright owners and it is a condition of accessing publications that users recognise and abide by the legal requirements associated with these rights.

\section{Takedown policy}

If you believe that this document breaches copyright please refer to the University of Manchester's Takedown Procedures [http://man.ac.uk/04Y6Bo] or contact uml.scholarlycommunications@manchester.ac.uk providing relevant details, so we can investigate your claim.

\section{OPEN ACCESS}




\title{
Environmental Challenge: How to close the gap between policy and technology?
}

\author{
Holger Pfänder*, Peter Hollingsworth ${ }^{\dagger}$, Hernado Jimenez ${ }^{\ddagger}$, Henry Won $\S$ \\ Georgia Institute of Technology, Atlanta, Georgia 30332, USA
}

The recent increase in focus on climate change in the US, brought on by the results of the November 2008 elections; along with the economic stimulus package passed in the winter of 2009 illuminated the need for a capability to rapidly assess the gap between the policies being proffered and the technology portfolios currently under development in various research \& development establishments. This paper demonstrates one such capability, developed for NASA's Subsonic Fixed Wing Project, as a means of rapidly looking at what technology combinations might help close the gap between the current trends and different proposed policies. It makes use of a rapid technology modeling process and parts of the US FAA's environmental analysis tool suite. The process is demonstrated using a set of different technology "futures" ranging from "frozen", to including a range of systems proposed by NASA and compares them to different policy goals.

\section{Nomenclature}

$\begin{array}{ll}\text { ACARE } & \text { Advisory Council for Aeronautics Research in Europe } \\ \text { BTS } & \text { (US) Bureau of Transportation Statistics } \\ \text { CAEP } & \text { (ICAO) Committee on Aviation Environmental Protection } \\ D_{p} / F_{00} & \text { LTO Emissions Characteristic Value } \\ \text { EDS } & \text { Environmental Design Space } \\ \text { EI } & \text { Emissions Index } \\ \text { ETS } & \text { Emissions Trading Scheme } \\ \text { FAA } & \text { (US) Federal Aviation Administration } \\ \text { GWP } & \text { Global Warming Potential } \\ \text { IATA } & \text { International Air Transport Association } \\ \text { ICAO } & \text { International Civil Aviation Organization } \\ \text { IPCC } & \text { (UN) Intergovernmental Panel on Climate Change } \\ \text { JPDO } & \text { Joint Planning and Development Office } \\ \text { LDN } & \text { Day, Night Noise Level } \\ \text { LTO } & \text { Landing and Take-Off (Cycle) } \\ \text { MMTCE } & \text { Million MTCE } \\ \text { MTCE } & \text { Metric Tons Carbon Equivalent } \\ \text { MAGENTA } & \text { Model for Assessing Global Exposure to the Noise of Transport Aircraft } \\ \text { NASA } & \text { (US) National Aeronautics \& Space Administration } \\ \text { NEPA } & \text { (US) National Energy Policy Act } \\ \text { NHTSA } & \text { (US) National Highway Transportation Safety Administration } \\ \text { RPK } & \text { Revenue Passenger Kilometer } \\ \text { SAGE } & \text { System for Assessing Aviation's Global Emissions }\end{array}$

\footnotetext{
*Research Engineer II, Guggenheim School of Aerospace Engineering, Georgia Institute of Technology, Atlanta, GA , holger.pfaender@ae.gatech.edu, AIAA Member

${ }^{\dagger}$ Former Research Engineering II, Guggenheim School of Aerospace Engineering, Atlanta, GA, Current Lecturer, School of MACE, The University of Manchester, Manchester, Great Britain, peter.hollingsworth@manchester.ac.uk, AIAA Member

${ }^{\ddagger}$ Graduate Research Assistant, Guggenheim School of Aerospace Engineering, Atlanta, GA, AIAA Student Member

$\S$ Former Graduate Research Assistant, Guggenheim School of Aerospace Engineering, Atlanta, GA
} 


\section{Introduction}

Recently there has been an increasing discussion about the effects off aviation on the environment. This has been taking place due to increased awareness about the limits of available fuel resources, the potential impact on the environment and climate, as well as political concerns about the security policy implications. This discussion has been taking place even though admittedly aviation only contributes a relatively small percentage of the overall emissions of man-made emissions into the atmosphere. This is due to the fact that aviation and air travel has been steadily growing since its a availability. This growth has the effect off counterbalancing efforts to improve the efficiency and fuel burn as well as emissions reductions off new aircraft designs entering service. An additional concern is that aviation emits most of its emissions at high altitudes, where the contention is that many emissions have a larger impact on climate than ground based emissions.

It is important to realize that technology improvements largely take place at the aircraft or aircraft subsystem level, whereas policy is usually formulated at the national or global system-level. In this case system level refers to the entire air traffic system or the national level in terms of energy consumption. Obviously both levels are dependent on one another. That is, introducing new technologies into the operational fleet of aircraft has the effect of reducing fuel use and or reducing particular kinds of emissions and/or noise exposure. These three areas of aviation impacts on the environment and people actually represent a trade-off for the aircraft designer. Only introducing new technologies or technology packages will shift the Pareto efficient trade-off surface between those impacts. Quantifying the impact of the introduction of a new technology aircraft is much more challenging than introducing a percent reduction for a particular size and/or market of existing or future flights. Furthermore, there is also a nontrivial mapping between passenger air travel demand and flights that airlines perform in response to passenger demand. Therefore, this paper introduces a model of linked surrogate models, each representing the particular areas alluded to earlier, to allow the rapid exploration of different options such as introducing different technologies in various states as well as comparing the resulting system level results to particular policy goals. The set of policy goals chosen for this paper are the goals taken from the energy plan from Obama's campaign. Subsequently the House passed H.R. 2454: American Clean Energy and Security Act of 2009. Until further clarifications and updates of these goals are published they were used to show the impact of NASA's Subsonic Fixed Wing Project's (SFW) technologies as well as to show some potential ways of closing the gap between existing programs and policy goals.

\section{Background}

\section{II.A. IPCC and Aviation}

The Intergovernmental Panel on Climate Change publishes reports on the various aspects of climate change. Among those publications is a report on aviation and the global atmosphere, which was published in $1999 .^{1}$ This report contains an overview of the effects of aviation related emissions on the global atmosphere. The results are based on a number of scenarios ranging from low to high growth estimates. The scenarios for aviation are based on scenarios published in a special report about a mission scenarios. ${ }^{2}$ This has been updated since then in $2005 .{ }^{3}$ These scenarios in turn are based on work by the Committee on Aviation Environmental Protection (CAEP) which is part of the International Civil Aviation Organization (ICAO). These scenarios include assumptions about the overall fleet efficiency of aviation extrapolated from historic trends. However, they do not include specific technologies or aircraft. These reports focus generally on the impact aviation has on the environment in terms of the specific strength of radiative forcing of the emissions, especially at altitude versus the vicinity of airports. These studies tend to not include specific goals outside of the Kyoto protocol or CAEP rule making, which currently does not regulate $\mathrm{CO}_{2}$. In general these studies focus more on a potential stabilization of the $\mathrm{CO}_{2}$ concentration in the atmosphere or an interrelated goal of limiting the absolute increase in overall average global temperature. 


\section{II.B. European Trading and ACARE Goals}

These reports generally serve as the foundation for limiting the $\mathrm{CO}_{2}$ emissions to certain levels in cap-andtrade schemes, which have been proposed or in the case of Europe have already been implemented. Aviation is targeted to be covered under the European Emissions Trading Scheme (ETS) by 2012. There are of course other goals specific to Europe. For example, the Advisory Council for Aeronautics Research in Europe (ACARE) published goals and its strategic research agenda ${ }^{4,5}$ with an update in $2008 .{ }^{6}$ These goals are based on the Vision 2020. This set of goals simply states a $50 \%$ reduction in $\mathrm{CO}_{2}$ emissions per passenger kilometer and $\mathrm{NO}_{\mathrm{X}}$ by $80 \%$, which are specific aircraft related goals.

\section{II.C. Goals for Aviation in the United States}

Goals and regulations pertaining to aviation in the United States are promulgated by a number of different sources. On one hand, The US Environmental Protection Agency (EPA), which governs local air quality compliance, has rules pertaining to the airports and their immediate surroundings. However, these rules only include emissions with direct health effects such as $\mathrm{NO}_{\mathrm{X}}$ and particulate matter but do not include $\mathrm{CO}_{2}$ and other emissions which are not considered local pollutants. Furthermore, the EPA does not have specific regulatory authority over aviation, this is maintained by the Federal Aviation Administration (FAA), which sets certification and compliance rules. At the same time the FAA and, therefore, the US JPDO have technology goals pertaining to improvements in aircraft fuelburn and noise performance. ${ }^{7}$ In neither case are specific $\mathrm{CO}_{2}$ or $\mathrm{NO}_{\mathrm{X}}$ goals given by the FAA.

At the time of writing the new US presidential administration had not yet issued any revisions to the goals given by the FAA or EPA. However, there indications that the long-term policy of the US might be changing. First, President Obama during his presidential campaign published a long-term energy and climate position document. ${ }^{8}$ This document sets a goal of returning the US to $1990 \mathrm{CO}_{2}$ emissions by the year 2020 and a further $80 \%$ reduction from 1990 levels by the year 2050. The plan sets out that this would be achieved with an emissions trading scheme with a $100 \%$ allowance auction. This translates into a situation where all of the credits for emissions would have to be purchased on the open market.

Additionally, during the last few years there have been moves by individual states to regulate the $\mathrm{CO}_{2}$ emissions produced by other forms of transportation, most notably California's decision to set higher fueleconomy standards for automobiles sold in that state. ${ }^{9}$ Subsequently several more states adopted the California rules. The federal government, denied California the right to set higher standards saying that federal rules preempted the state rules. ${ }^{10}$ However, the US Ninth Circuit Court of Appeals ruled that $\mathrm{CO}_{2}$ is a pollutant that must be regulated according to the National Energy Policy Act (NEPA) and the Clean Air Act, ${ }^{11}$ and as such the National Highway Traffic Safety Administration (NHTSA) and the EPA must produce an environmental impact statement on their decision to bar California's regulation. This plus the recent decision by the Obama Administration to revisit California's petition ${ }^{12}$ indicates that additional $\mathrm{CO}_{2}$ regulations and goals will be forthcoming. In June the House also passed HR2454 titled the "American Clean Energy and Security Act of 2009" sponsored by Rep. Henry Waxman and Rep. Edward Markey. ${ }^{13}$ The carbon cap and trade scheme detailed therein, in principle has the same overall reduction goals as the Obama campaign goals. The major exception is that there is a short term goal for 2012 and no goal for 2040 and that the baseline reference year has been moved from 1990 to 2005. The goals are shown in Table 1. It is also important to note that the bill specifies not just $\mathrm{CO}_{2}$ but rather greenhouse gases, of which seven primary gases and others to be added are specified. However, all gases covered are converted into metric tons carbon equivalent (MTCE), based on their 100 year global warming potential (GWP).

Table 1. H.R. 2454 Greenhouse Gas Reduction Targets for Specified Sources from 2005

\begin{tabular}{|c|c|}
\hline Year & Percent \\
\hline 2012 & 97 \\
\hline 2020 & 83 \\
\hline 2030 & 58 \\
\hline 2050 & 17 \\
\hline
\end{tabular}


Another US organization that has set emissions goals is NASA. In particular NASA's Subsonic Fixed Wing Project (SFW) has specific vehicle level goals. Along with these goals comes an expectation of knowing these technologies would be implemented in a vehicle that would be introduced into service at a particular time. The vehicle system level corner points of the design space are shown in Table 2.

Table 2. NASA SFW Technology Goals at the Aircraft System Level for Three Generations of Future Aircraft. ${ }^{14}$

\begin{tabular}{|c|c|c|c|}
\hline $\begin{array}{c}\text { CORNERS OF THE } \\
\text { TRADE SPACE }\end{array}$ & $\begin{array}{l}\mathrm{N}+1(2015)^{\star * \star} \\
\text { Generation } \\
\text { Conventional Configurations } \\
\text { relative to } 1998 \text { reference }\end{array}$ & $\begin{array}{l}\mathrm{N}+2(2020)^{* * *} \\
\text { Generation } \\
\text { Unconventional Configurations } \\
\text { relative to } 1998 \text { reference }\end{array}$ & $\begin{array}{l}\mathrm{N}+3(2025)^{* * *} \\
\text { Generation } \\
\text { Advanced Aircraft Concepts } \\
\text { relative to user-defined reference }\end{array}$ \\
\hline Noise & $\begin{array}{c}-32 \mathrm{~dB} \\
\text { (cum below Stage 4) }\end{array}$ & $\begin{array}{c}-42 \mathrm{~dB} \\
\text { (cum below Stage 4) }\end{array}$ & $\begin{array}{c}-71 \mathrm{~dB} \\
\text { (cum below Stage 4) }\end{array}$ \\
\hline $\begin{array}{l}\text { LTO NOx Emissions } \\
\text { (below CAEP 6) }\end{array}$ & $-60 \%$ & $-75 \%$ & better than $-75 \%$ \\
\hline $\begin{array}{c}\text { Performance: } \\
\text { Aircraft Fuel Burn }\end{array}$ & $-33 \% * *$ & $-40 \% * *$ & better than $-70 \%$ \\
\hline $\begin{array}{l}\text { Performance: } \\
\text { Field Length }\end{array}$ & $-33 \%$ & $-50 \%$ & exploit metro-plex* concepts \\
\hline
\end{tabular}

It should be noted that none of the goals can be achieved in a realistic design at the same time but rather represent the extremes of the possible trade-offs. For example, it would not be possible to meet the fuelburn reduction and $\mathrm{NO}_{\mathrm{X}}$ reduction targets at the same time. Instead, it is only possible to meet one of the stated goals by giving up improvements in the other goals.

\section{Technologies}

Historically any future technology or policy has been compared to the current generation of systems no matter how far in the future the new technology or policy will enter service or come into effect. This a reasonable assumption for policies or technologies that will become active in the next several years. However, in this paper we are looking at technologies and policy goals that are still twenty plus years away. This means that ideally benefits of the technology must be assessed against what would otherwise be the status quo. This is not a trivial task since it is fairly hard to predict what technologies industry would focus on. Historically most of the analysis was done using a de-facto perpetuation of the status-quo, what we will term "frozen" technology. That is aircraft in operation today will be replaced with, and growth will be accomplished with aircraft that are currently in production. Table 3 has a list of the aircraft that were used, for this work, as replacements in the baseline "frozen" technology exploration. However, this is not ideal since we already know that there is a generation of new aircraft, beyond those that are used for a "frozen" technology assumption, that will be coming online in the next decade. To neglect these new systems overstates the problem with the status-quo and tends to overstate the performance of new technologies. These new aircraft, which for the purpose of this paper these are termed "Anticipated Industry Response", do not exist in the modeling tools. Therefore it was necessary to develop a method to represent them. This method is described in the following section. Furthermore, the same methods that are used to model these new industry vehicles are applicable to modeling the NASA technologies and aircraft concepts, that will be discussed later.

\section{III.A. Modelling New Aircraft \& Technologies}

The goal of several of the efforts that stimulated this research was to quickly analyze the potential effect of new technologies on the environmental performance of the air transportation system. Further many of these technologies effect more than one aspect of the aircraft. For example hybrid laminar flow control would both 
Table 3. Frozen Technology Best in Class Replacement Aircraft.

\begin{tabular}{|c|c|c|c|}
\hline Class & Aircraft & Engine & Production Cessation Date \\
\hline 50 & ERJ145 & 6AL016 & 2039 \\
\hline 99 & CRJ900 & 8GE103 & 2039 \\
\hline 150 & B737-7, A319-1 & 8CM064, 8CM057 & 2022 \\
\hline 210 & B737-8, A320-2 & 8CM066, 8CM058 & 2022 \\
\hline 300 & B777-2, A330-2 & 7GE097, 3RR030 & $2032 / 2019$ \\
\hline 400 & B777-3, A340-6 & 7GE099, 8RR045 & 2032 \\
\hline 500 & B747-4 & 3GE057 & 2013 \\
\hline 600 & B747-4 & 3GE057 & 2013 \\
\hline $600+$ & B747-4 & 3GE057 & 2013 \\
\hline
\end{tabular}

improve the aircraft cruise lift-to-drag ratio but also hurt the propulsion systems specific fuel consumption. Becasue of this the common methods of applying adders or multipliers to existing aircraft models after the airspace tools were run was deemed to miss potentially important secondary effects. Furthermore, in the case of many new aircraft designs the improvements are often quoted either at a specific point, such as a fuelburn reduction per passenger carrying a specific load factor of payload over a specific range, or in terms of a cost of ownership reduction that is based upon a specific usage scenario. While these are useful for a very quick comparison they will often not correlate well with different usage scenarios. For instance an aircraft with a quoted $20 \%$ fuel burn reduction on missions of 6,500 nautical miles will often have a significantly lower fuelburn savings on missions of 500 nautical miles.

To compound the issue there was, at the start of this effort, a distinct lack of publicly available advice or standard practice for even creating new models for many of the tools. The FAA had issued a data request package for incorporating new aircraft in the INM model. ${ }^{15}$ However, while this described how to create the appropriate representation from flight test or pilots manual data, it had no direct insight into how to account for new technologies. Furthermore, at the time of research there was precious little information on how to incorporate new aircraft of technologies into the airspace and environmental modeling tools, either ACES, BADA,${ }^{16}$ or AEDT. ${ }^{17,18}$ Since this work was completed a updated version of BADA has been released. ${ }^{16}$ Accompanying this release is a technical note that describes the process to create new BADA models; however, like the FAA's process for INM this method is focused on flight test, operational, or pilot's handbook data. ${ }^{19}$

The process of developing new aircraft performance models starts with the identification of one or more similar aircraft models that currently exist in either the BADA ${ }^{16}$ and/or the SAE- $1845^{20}$ data sets. At the same time technology and future performance data are collected to determine performance, noise, and emissions improvements for the future aircraft. This information is then used to develop the new performance models. The development of new vehicle models from the baseline models is a three-part process.

1. Determine or match performance fuelburn over a range of missions

2. Adjust emissions indices to match engine emissions improvements

3. Adjust NPD and spectral information to achieve improved performance

A basic outline of two of the three steps of the process is included in the following sections. Since this paper focuses on the fuelburn and emissions aspect of the analysis, as that is the focus of the policies in question, the noise modeling description has been omitted for clarity.

\section{III.A.1. Aircraft Performance and Fuelburn}

The first step of the process is the most important as it determines the overall performance of the vehicle concept in the airspace, and consequently the safety impacts, capacity improvements, and ultimately environmental impact. The second two steps are specifically necessary to capture the full range of environmental 


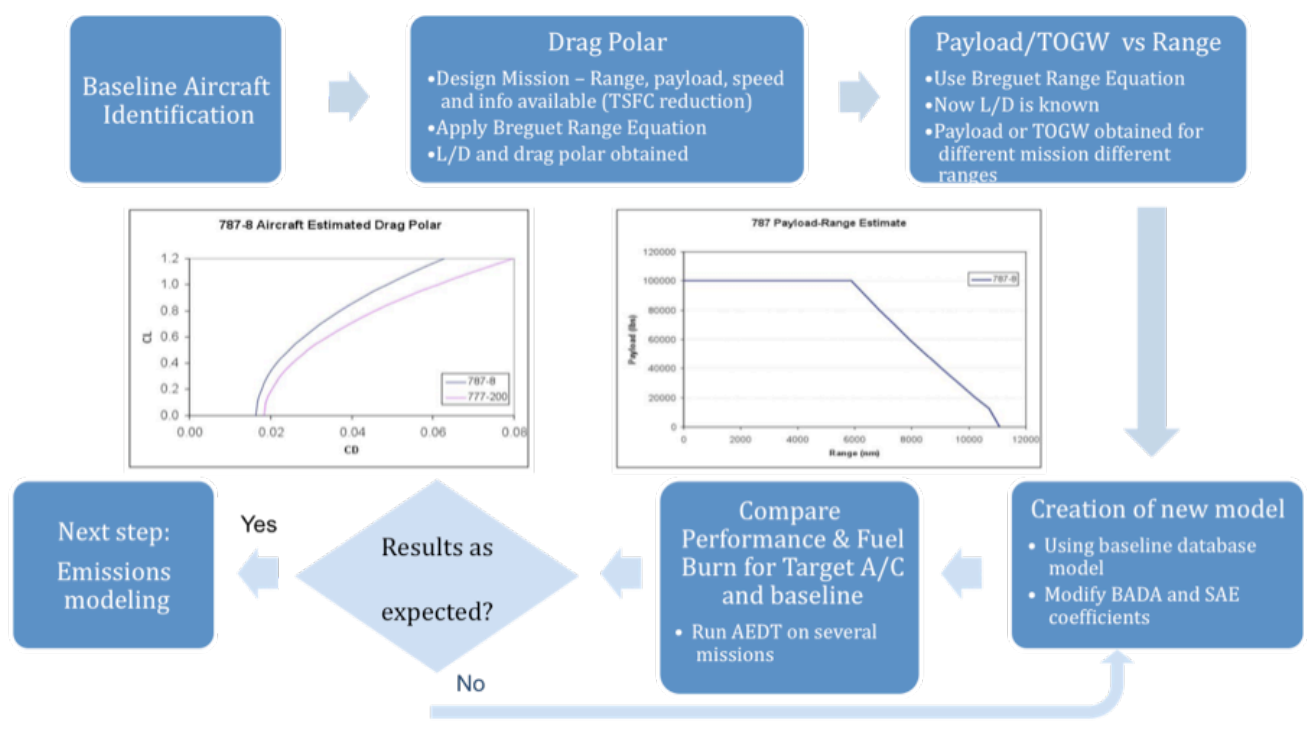

Figure 1. Fuelburn Matching Process Flowchart, adapted from ${ }^{21,22}$

improvements that are measured using the AEDT and APMT toolsets. The general flow of this process is shown in Figure 1.

The iteration about drag-polar, specific fuel consumption and payload and range are either performed using a simple Breuget basis or for more detail simplified model in NASA's Flight Optimization System (FLOPS) code. Regardless of the approach the performance of the generated coefficients, both BADA and AIR-1845, can be investigated using a tool similar to AEDT's Aircraft Performance Module (APM) ${ }^{18}$ which implements both BADA and AIR-1845. This ensures that field, departure, enroute, and arrival performance meet both the needs of the vehicle concept and provide sufficient margin to ensure safe operation through a variety of airspace concepts. Once the vehicle performance and fuelburn are determined the resulting BADA coefficients and general performance metrics are passed on for use in the procedure development and evaluation tools. The second and third steps in the high-level characterization process are specific to the environmental impact-modeling portion of the procedure analysis. This portion is undertaken using the FAA's AEDT toolsuite. AEDT implements both BADA and AIR-1845 equations to determine aircraft performance and fuelburn throughout the full range of the flight envelope. It also implements the Boeing fuelflow method (BFFM) ${ }^{23}$ to determine emissions and AIR-1845 and ECAC Doc 29 ${ }^{24,25}$ to estimate noise impact. More detail on the environmental modeling process is described in an associated abstract.

\section{III.A.2. Creating Emissions Indices}

The process to estimate the appropriate emissions indices for each of the ICAO certification ${ }^{26,27}$ points is shown in Figure 2. The development of new emissions indices (EI) is based upon what technology improvements are expected for each of the engine types. These improvements can be classified in one of two key ways: a direct reduction in the specific EI or often an adjustment of the EIs to meet a change in margin to the CAEP certification limits. The specific limits and means of determining the certification values for each of the regulated emissions are contained in Volume II of Annex 16 to the ICAO convention. ${ }^{27}$ In the case of a direct improvement to the emissions the EIs are changed accordingly. At the same time the reference fuel flows that correspond to each of the EIs must be adjusted to reflect any fuelburn improvements for the new vehicle concept. This prevents the case where the fuelflow in simulation either exceeds the maximum value or is less than the minimum value contained in the data. This is necessary due to limitations in the BFFM method. For cases where improvements to the regulatory margin are specified a more detailed process is undertaken. Each of the ICAO/CAEP emissions regulations is expressed in terms of what is know as the Emissions Characteristic or $\mathrm{D}_{\mathrm{p}} / \mathrm{F}_{00}$, measured in units of grams of emissions per kiloNewton of thrust. This is measured over the ICAO Landing and Take-off (LTO) cycle. The result of this is that there is a functional relationship between individual EIs, their corresponding fuelflow, and the ICAO specification 


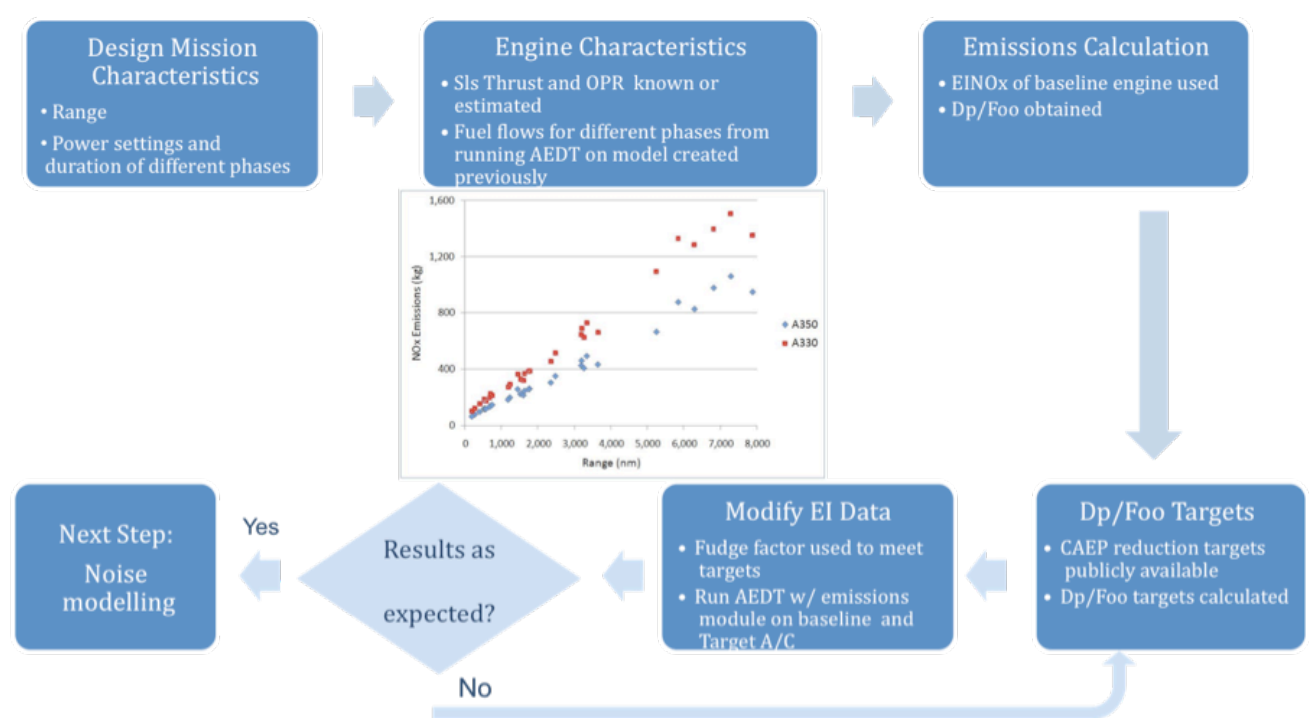

Figure 2. Emissions Index Determination Flow, adapted from ${ }^{21,22}$

that determines the final Characteristic. The details of this process are beyond the scope of this paper but can be found in Annex 16 of the ICAO convention. ${ }^{27}$ A further complication is that each of the regulatory limits is a function of external parameters, for instance the $\mathrm{NO}_{\mathrm{X}}$ is a non-smooth function of the engine thrust and sea-level static overall pressure ratio. This means that any technology improvement or redesign that changes the thrust or overall pressure ratio of the engine must be taken into account. The resulting, multi-step process is described here-in:

1. Calculation of the new regulator limit based upon updated engine thrust and overall pressure ratio estimations

2. Adjust the fuelflows to meet the fuelburn changes determined in the performance and fuelburn step of the characterization

3. Determination of current system emissions characteristic $\mathrm{D}_{\mathrm{p}} / \mathrm{F}_{00}$ value using ICAO Annex 16

4. Identification of change in characteristic value required to meet the estimated margin

5. Change the corresponding EIs to mach the needed change in emissions characteristic

In both the direct reduction and margin based cases the changes in EI are applied uniformly across all fuelflows.

\section{III.B. Anticipated Industry Response}

First, let's look at key vehicles industry is likely to introduce in the near term future. This includes the major commercial aircraft launch manufacturers have committed to, as shown in Table 4. It should be noted that the A380 already is in operation. However, environmental the full environmental performance data did not become available until shortly before publication of this paper. Additionally, several projects in the 50 and even the small end of the 99 seat category have been committed to recently. The new systems have not been included in the analyses for this paper due to limited availability of estimates of environmental impact, at the time the work was performed. It is anticipated that these aircraft could be included in future updates.

\section{III.C. NASA Technology Implementation on Aircraft}

Historically, NASA has established their technology goals for future generations of aircraft by either comparing the advanced technology version of an aircraft to a baseline vehicle at one single point in its operational envelope, or by comparison to one of the ICAO certification standards. ${ }^{27-29}$ This has meant that it is often 
Table 4. Anticipated Industry Production Replacement Aircraft.

\begin{tabular}{|c|c|c|c|}
\hline Class & Introduction Date & Aircraft & Engine \\
\hline 50 & - & - & - \\
\hline 99 & - & - & - \\
\hline 150 & - & - & - \\
\hline 210 & - & - & - \\
\hline 300 & $2010 / 12,2014$ & $\mathrm{~B} 787-8 / 9, \mathrm{~A} 350-9$ & - \\
\hline 400 & 2016 & $\mathrm{~A} 350-10$ & - \\
\hline 500 & 2011 & $\mathrm{~B} 747-8$ & GENX \\
\hline 600 & 2011,2008 & $\mathrm{~B} 747-8, \mathrm{~A} 380-8$ & GENX, 8RR046 \\
\hline $600+$ & 2008 & $\mathrm{~A} 380-8$ & $8 \mathrm{R} 046$ \\
\hline
\end{tabular}

quite difficult to gauge the level of global benefit that will be achieved through the adoption of any one or set of technologies. In the most recent round of solicitations, for the SFW "N+3" vehicle and technology projects, NASA has started to use a more global metric for noise. The have supplanted a margin to Chapter/Stage 3 or 4 with a $\mathrm{L}_{\mathrm{DN}}$ goal. ${ }^{28}$ However, for other generations of NASA technology development, "N+1" $\&$ " $\mathrm{N}+2$ ", and for the fuelburn and emissions metrics for the " $\mathrm{N}+3$ " program a relationship between the actual technology performance and the system level metrics needs to be established. The NASA technology aircraft concepts investigated are given in 5 .

Table 5. NASA SFW New Technology Aircraft.

\begin{tabular}{|c|c|c|}
\hline Class & Introduction Date & Aircraft \\
\hline 50 & 2035 & $\mathrm{~N}+3-1$ \\
\hline 99 & 2035 & $\mathrm{~N}+3-2$ \\
\hline 150 & 2018,2035 & $\mathrm{~N}+1-1 / 2, \mathrm{~N}+3-2$ \\
\hline 210 & 2018 & $\mathrm{~N}+1-2 / 3$ \\
\hline 300 & $2022 / 2028$ & $\mathrm{~N}+2-1$ \\
\hline 400 & $2022 / 2028$ & $\mathrm{~N}+2-1 / 2$ \\
\hline 500 & $2022 / 2028,2035$ & $\mathrm{~N}+2-2, \mathrm{~N}+3$ VLA \\
\hline 600 & 2035 & $\mathrm{~N}+3$ VLA \\
\hline $600+$ & 2035 & $\mathrm{~N}+3$ VLA \\
\hline
\end{tabular}

\section{System Level Analysis}

The primary reason that most technologies have not been investigated for their system level effects is that, until recently, it has been computationally unfeasible to perform more than a rudimentary assessment. This problem arose for two reasons. First, most computers did not have sufficient processing power or storage to make it economically viable. Second, the tools available were not designed for large scale batch runs with many new aircraft types. This has changed significantly in recent years. The development of tools like the FAA's SAGE ${ }^{30}$ and MAGENTA ${ }^{31}$ global emissions and noise modeling tools paved the way for large scale batch runs. Further, the current development of the new Aviation Environmental Design Tool (AEDT) promises to further simplify the investigation of large scale technology sets. ${ }^{17,18}$ This has made the assessment of individual or a set of technologies feasible; specifically this improved capability is one of the enabling technologies for the FAA's Environmental Design Space (EDS) detailed technology interdependency tool. ${ }^{32,33}$ 
While each of the above tools provides an additional capability towards modeling the effect of a technology and/or policy, they are not specifically designed to enable the rapid, near real time investigation of a wide variety of technologies, procedures and policies against a varying set of goals.

\section{IV.A. Environmental Analysis}

The environmental analysis starts with the selection of a baseline year for which a quality data set is available. The baseline operations set used for this analysis is the 2005 baseline operations set used for the CAEP/8 sample problem. This set consists of a worldwide set generated from radar and other schedule data from a number of worldwide sources. It consists of roughly 82,000 unique origin-destination-aicraftengine combinations containing aggregate annual operation counts. It should be noted that the data set primarily focuses on commercial aviation in the 50 seat and larger categories. Therefore, general aviation, small aircraft, and small airlines are not included in this analysis.

This baseline year data then has to undergo a transformation into out-year projections that assign new operation counts to origin-destination pairs as well as reassign aircraft-engine combinations. This process is in reality very complex and as such some simplifying assumptions have to be made. The primary assumptions are that the origin-destination routes do not change, which means no new airports or routes are added or removed completely, however, large shifts between routes are permitted, though unlikely to occur. Additionally, no capacity constraints are enforced. The first step in producing an out-year operations count is to grow revenue passenger kilometers (RPKs) as specified for the CAEP/8 analysis. This growth is specified by grouping origin-destination pairs into generalized route groups and assuming that they generally will grow at similar accepted levels. Additionally, CAEP/8 style improvements in load factor and utilization were applied also, both of which moderate the growth by essentially increasing the amount of passenger demand that can be satisfied with existing operations and equipment.

The next step is to retire existing aircraft. This is accomplished by utilizing the CAEP/8 survival curves and reducing the operations by those existing aircraft by the appropriate percentages based on the fleet age and distribution. Once the operations have been grown and retired, there are remaining operations which are already assigned to specific aircraft-engine combinations. Additionally, there are unassigned operations, which were produced by growth and the retiring of aircraft. These operations have to be assigned to new aircraft-engine combinations.

The assignment in this analysis was decided to initially consist entirely of the frozen technology aircraftengine combinations as shown in Table 3. For the purpose of this analysis two primary scenarios were considered. A purely frozen technology scenario in which these aircraft-engine combinations are used as replacements ad infinitum. The other scenario consists of a combination of all the combinations shown in Tables 3,4,5. Some of the vehicles stated do overlap in size class and timeliness of availability. If this is the case they are even split among the replacements that need to be covered by them. This is the reason why some of the current technology and even some near future aircraft have production cessation dates. This allows a more complete replacement with much more advanced aircraft-engine combinations in the very far out years.

Once this is completed, each unique origin-destination-aircraft-engine combination can then simply be processed through AEDT. However, since this means roughly 150,000 unique cases for every out-year to be analyzed, the first step in limiting the size of the analysis was to focus only on data for the years 2010, 2020, 2030, 2040, and 2050. This still brings the amount of lines of data to be analyzed to roughly 750,000 .

\section{IV.B. Enabling Rapid Scenario Analyses}

This means that not only have the aircraft-engine assignments be derived parametrically from the growth assumptions and retirement curves, but also processed through AEDT. Normally, this would entail a large scale analysis effort requiring large database servers and powerful compute clusters.

\section{Results}

\section{V.A. Growth Forecasts}

This analysis primarily focuses on CAEP/8 growth assumptions. They are relatively aggressive in the short term and obviously do not include any data about the reduction in aviation traffic related to the current 
recession. Therefore, all the results were scaled to available Bureau of Transportation Statistics (BTS) total fuel data as reported on form P-21a for scheduled and unscheduled, domestic and international service for airlines greater than $\$ 20$ Million/year in revenue. Unfortunately, 2009 has only data available for the first six months, but is projected to show the largest drop in aviation fuel use followed by a slow recovery in the years after. Historically, the second half of the year shows significantly less fuel use that the first half. However, many forecasts, including the IATA forecast for the rest of 2009 show a rapid recovery in aviation. Therefore, this analysis assumes a simple duplication of the first half, which lies somewhere between the historical behavior and rapid recovery forecasts.

Other growth forecasts like the FAA Terminal Area Forecast (TAF) and the Long-Range forecast were tested. These forecasts generally less aggressive than the CAEP/8 growth assumptions. However, they are also more limited with regards to the range of the forecast. Since they do not cover the years out to 2050, this would require extrapolation of data, which in this case would lead to non-sensically large growth. These forecasts were therefore omitted in this analysis.

The other reason to adjust the results to actual data is to reduce the error introduced to the analysis by the many assumptions in the modeling process, which introduce analysis uncertainty that deviates from absolute values. However, careful review of the assumptions still allows for valid results comparisons between scenarios on a relative basis, as long as non of the assumptions underlying the analysis were violated or changed between the scenarios.

This analysis also focuses primarily on fuel burn, which directly translates into $\mathrm{CO}_{2}$ emissions. However, H.R. 2454 does cover many other species of emissions under the greenhouse gas category, but $\mathrm{CO}_{2}$ is by far the primary driver of the global warming potential. The results are all shown on a relative basis, but are converted into million metric tons carbon equivalent (MMTCE).

\section{V.B. Effects of Aircraft Technologies}

This section explains the effects of aircraft technologies applied to the various growth forecasts shown in the previous section. Shown in Figure 5 are several scenarios. The first scenario entitled "adjusted without technology" represents the baseline CAEP/8 growth and retirement assumptions. This scenario only utilizes the frozen technology aircraft as replacements without ever introducing any other aircraft or retirements of these current best-in-class aircraft. This serves as the baseline for the comparison of other technology introduction scenarios.

Initially, the analysis was to cover a variety of technology scenarios. However, it soon became evident that due to the long lead times in bringing new technology aircraft to market as well as the large inertia of the significant existing operational fleet and long lifetimes of aircraft, that significant deviations of the technology scenarios from the baseline only occur in limited fashion five to ten years after the introduction of a new technology aircraft. Therefore, only the full introduction of future industry aircraft, as well as all of the NASA concepts is shown as "adjusted with technologies". This shows that significant deviation from the baseline scenario only occurs in the year 2030 and beyond. It should also be noted that even the baseline scenario represents and improvement of the fleet, by replacing much older aircraft by in-production technology aircraft, but no new development of new technologies.

The "adjusted Greener By Design" is based on a relatively simple set of technology multipliers. ${ }^{34}$ These multipliers were applied instead of the 1999 FESG Scenario a growth - which in turn is based on an older CAEP analysis - to the CAEP/8 growth forecast. Additionally, the effects assumed starting from 2000 on were still applied, but the data was again adjusted to the 2009 reference data. The multipliers applied assume a rapid diffusion of new and aggressive technologies throughout the whole operational fleet with little inertia, regular engine updates and in the far out-years a significant shift in aircraft design to short design ranges as well as significant operational efficiency improvements and formation flying. Thus, the result is a significant improvement of the long term aviation $\mathrm{CO}_{2}$ emissions in the face of large growth. However, the goals shown are still far too aggressive and still show a significant gap.

\section{V.C. Effects of Carbon Charging Schemes}

Realizing, that there is an obvious gap between policy goals and the environmental impact forecasts based on growth and technology introduction, there is the obvious need for additional ways of closing the gap. This can be achieved in a number of ways. As mentioned before, H.R. 2454 establishes a carbon trading 


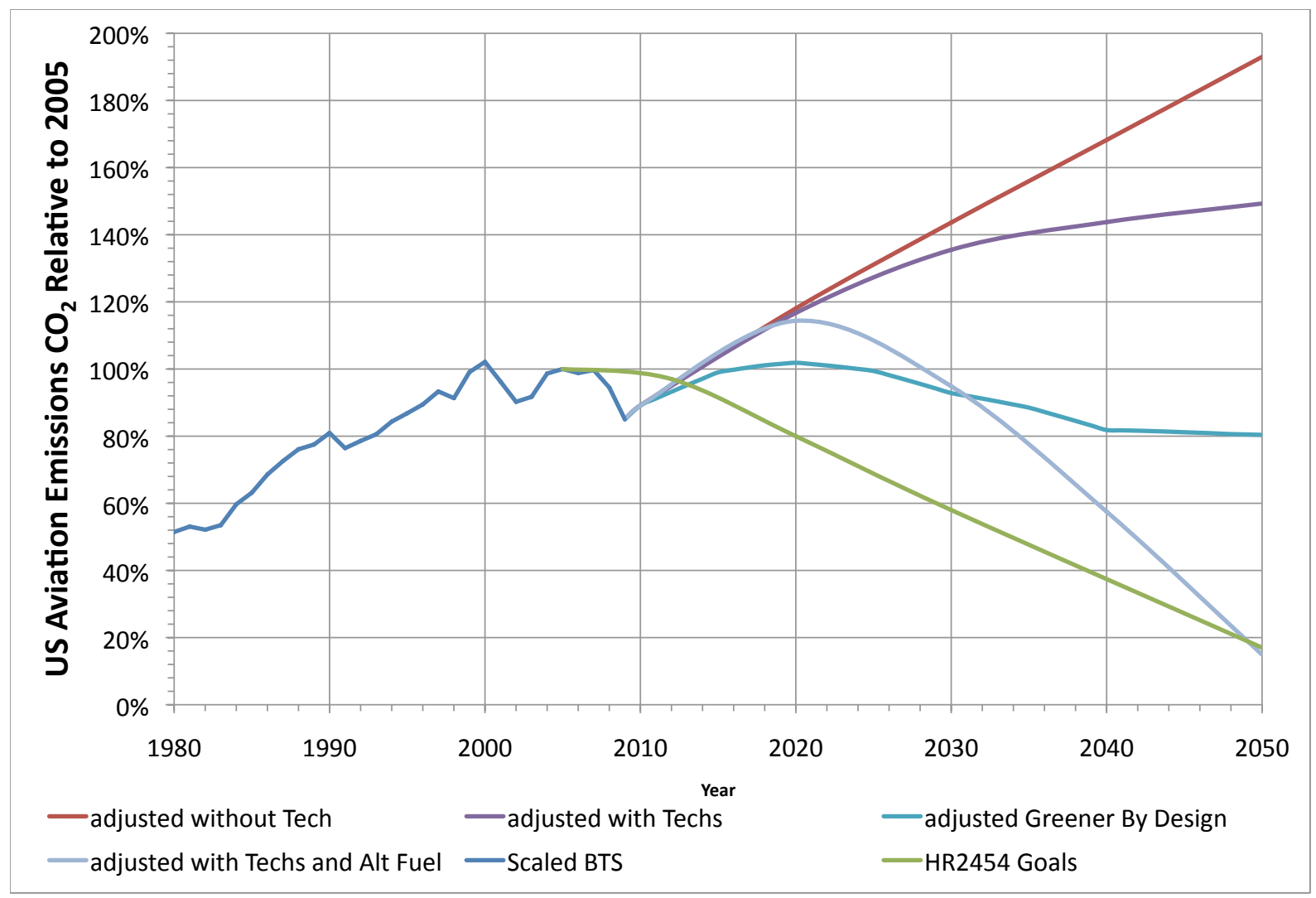

Figure 3. $\mathrm{CO}_{2}$ emissions for different scenarios of technology introduction based on CAEP growth and retirement assumptions.

scheme. Such a trading scheme provides a mechanism for industries where it is very expensive to reduce carbon output to purchase carbon credits at market prices.

So one corner point of the scenario space worth investigating, would be to assume at the difference between the policy goal and the actual carbon emissions as provided by the scenarios shown previously will be made up by aviation, and this probably means airlines, by purchasing carbon credits. This is a corner of the scenario space since it is likely that airlines will be unable to afford purchasing those carbon credits while maintaining a profitable business. It is possible to put a number on the cost to the aviation industry, however, the latest best estimate from the IPCC fourth assessment report ${ }^{35}$ indicates that the cost would be very high. However, there are large associated uncertainties in the social cost of carbon, which are due to unresolved uncertainties in the climate sensitivity as well as choice of discount rate, impact valuation, and treatment of equity. Therefore, the authors refrain from providing a specific value, but much further investigation is definitely needed, since this forms one of the corner points of the policy scenario space.

Another alternative would simply be to account for the purchase of carbon credits with an increase of ticket prices. This increase in prices would then lead to reduced passenger demand. Of course passenger demand has different market elasticities based on a number of factors such as trip purpose and trip distance. A survey of aviation passenger demand studies shows that in general business trips are relatively inelastic whereas leisure travel especially at short ranges can be very elastic, especially if other modes of transportation are readily available.

In this case it seems prudent to scale the number of flight operations proportionally to the survey study mean of the different elasticities. The amount of the reduction was scaled such that the policy goals were met. This assumption is equivalent to the airlines purchasing carbon credits and passing those charges directly to passengers. Additionally, this means that the price of carbon credits will be in equilibrium with all other transportation and energy sectors such that the policy goals are met. 


\section{V.D. Effects of Alternative Fuels}

The third way of meeting the policy goals is the introduction of alternative fuels. Due to the complexities of alternate fuels and their large dependency on their life cycle emissions from production and extraction over transport and refining to the final combustion, it is very difficult to make a good assessment of the potential available fuel choices. Furthermore, the details depend to a large degree on the details of carbon emission accounting specified in the bill. However, it is possible to assume that some type of alternative fuel would promise zero life-cycle carbon emissions. For the purposes of this work we will assume that such zero life-cycle carbon emissions alternative fuels will not count as carbon emissions of aviation to define the third corner of the policy trade space.

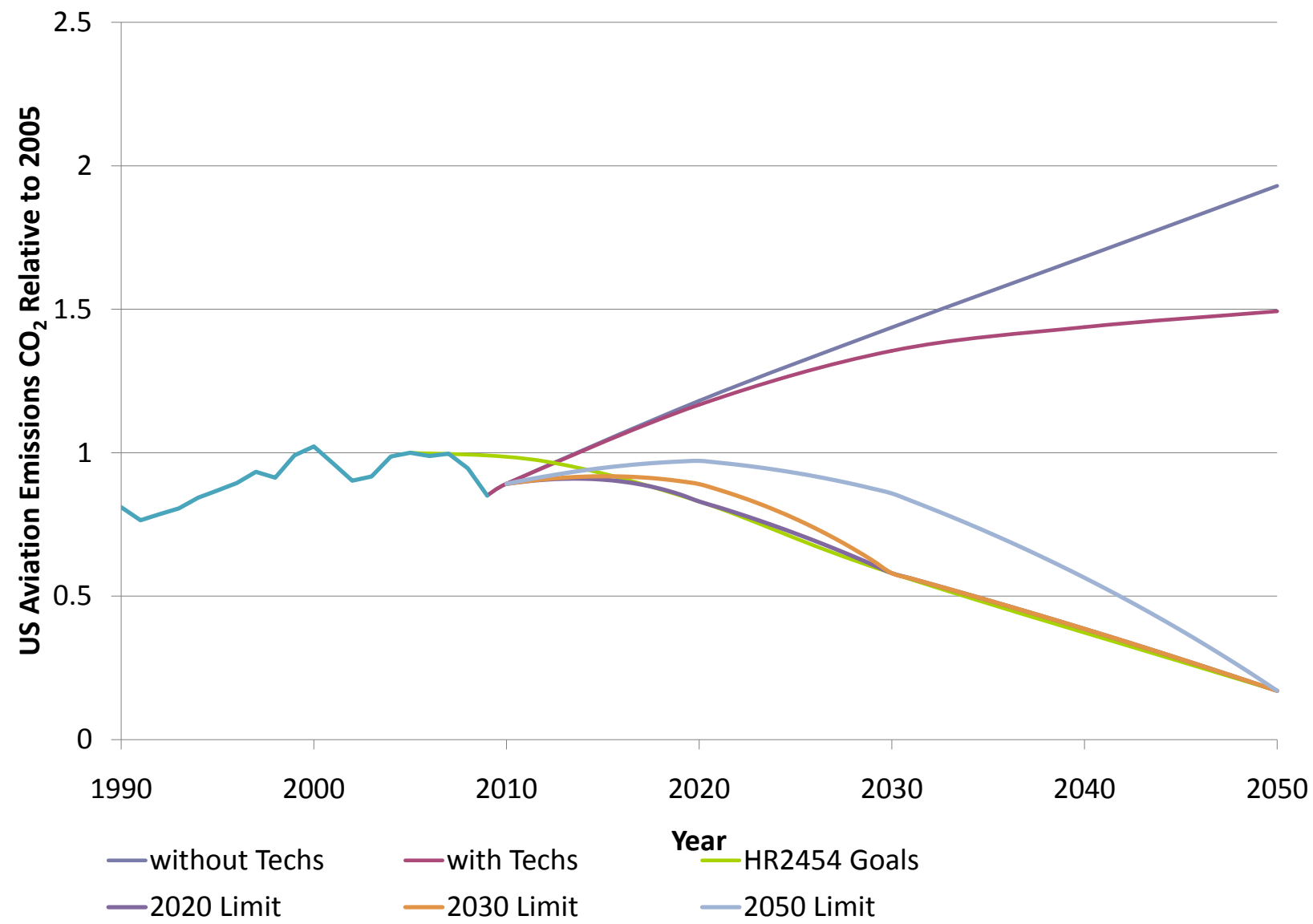

Figure 4. $\mathrm{CO}_{2}$ emissions for different scenarios of alternate zero net carbon fuel technology introduction to meet $\mathrm{H}$. R. 2454 goals.

Using this assumption means that we can effectively reduce the carbon emissions off aviation by simply replacing a certain amount of the fuel use with such zero life-cycle carbon emissions alternative fuels. This brings up another possible limitation, which is the availability of such fuels. It is unlikely that the specifications and certification of such a fuel would lead to availability in large quantities Therefore, we include an estimate of how much of the overall fuel use of aviation would have to be replaced by such alternative fuels.

\section{Conclusion}

\section{VI.A. Meeting Goals at a System Level}

The results of this analysis effort show that the amount of inertia resisting the rapid adoption of advanced technology aircraft caused by the large existing fleet is very significant. This means that any goals that would have to be met have to be conservative in the near term and only in the long term can significant 


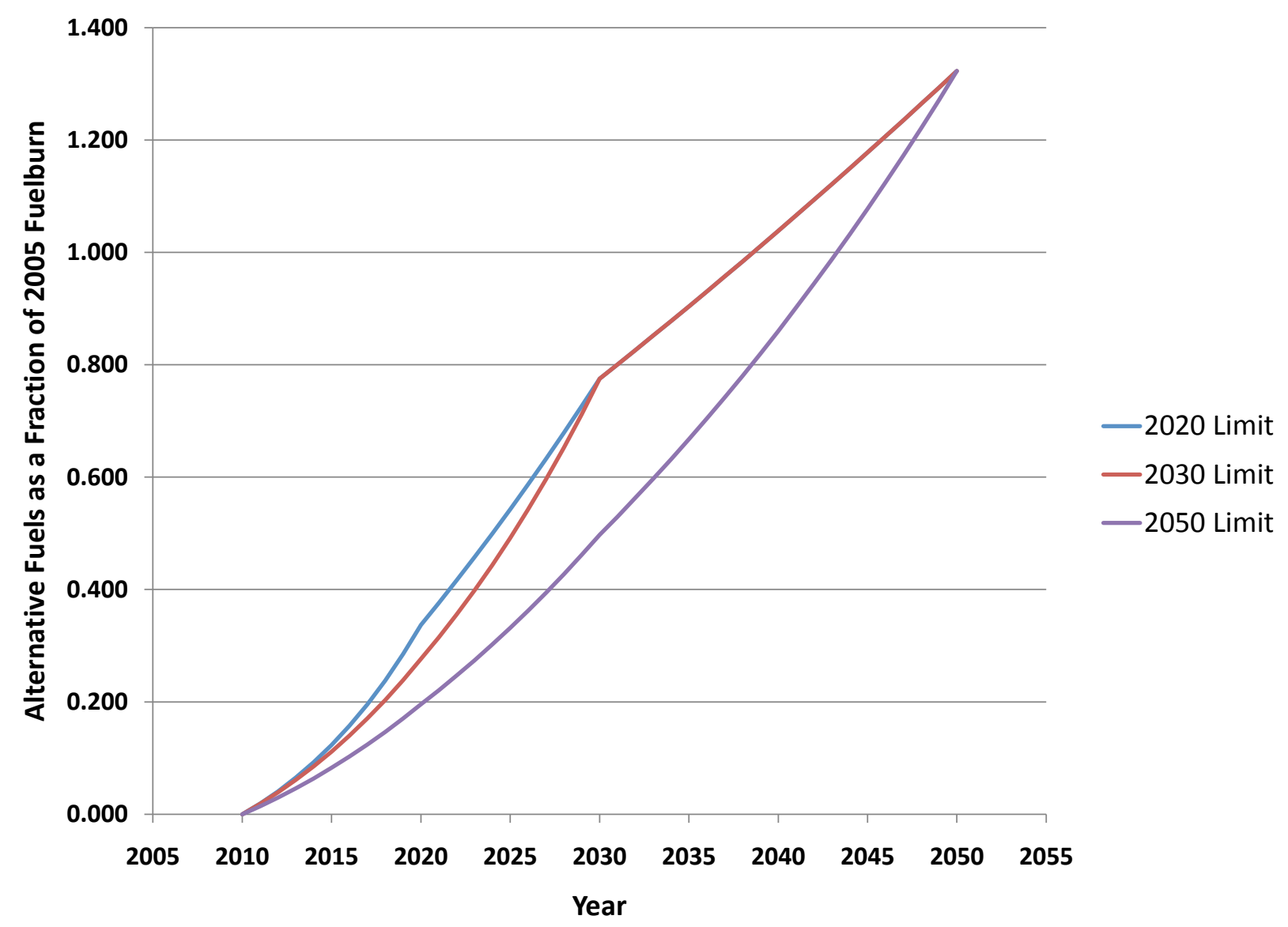

Figure 5. Alternate zero net carbon fuel amount required to meet H.R. 2454 goals by a certain year.

reductions in emissions be achieved. The current recession, however, made achieving the stated emission goals much easier by reducing the short term emissions as well as delaying the projected growth.

\section{VI.B. Balancing the Extremes}

The aggressiveness of the currently proposed emissions goals to be met under the proposed cap-and-trade system makes it difficult for aviation to meet these goals directly. They could be met by much more advanced technologies than analyzed here or more radical new designs. As shown by the analysis is to substitute a significant amount of fuel with a fuel that has little or no life cycle carbon emissions. However, the other simple way out is the purchase of emission allowances or offsets. Though this would incur additional cost for either the airline industry or be borne by the passenger by increased ticket prices. The first option seems unlikely since airlines already operate on very thin margins. So it is more likely that the cost would result in increased ticket prices, which in turn would result in reduced demand for air travel.

\section{VI.C. More Research Needed}

The exact amount of ticket price increase and the resulting reduction in air travel is highly dependent on the cost of the carbon emission allowances or offsets. In turn their price depends on overall economic activity and how difficult it is for other sectors covered by the cap-and-trade system to achieve the same goals. It is conceivable that there are large gains in efficiency easily achievable in other sectors. This would keep the price of emission allowances low and not cause a large increase in ticket prices. However, the reverse might also be true. This warrants further study. In general, estimating the cost of emission allowances is subject to a multitude of research topics. For the moment, it appears as if the introduction and use of an alternate fuel that has life cycle carbon emissions as close as possible to zero. None of the fuels currently 
under development have this characteristic by there are some candidates that would allow displacement of conventional fuel emissions is the proposed ratios.

\section{Acknowledgments}

This effort was sponsored under NASA Contract NNX07AO12A. The authors would like to thank Fay Collier for his support and insight into aviation technology development. Furthermore, the authors would like to acknowledge the FAA Office of the Environment Tools Development team, including the US DoT's Volpe Transportation Systems Center for the use of AEDT and support. Amongst this team the authors would especially like to thank Ralph Iovinelli of the FAA, David Senzing, Christopher Roof, \& Andrew Hansen of the Volpe center for their support. The authors would also like to thank the other members of the ASDL research team that supported this effort, including Gatien Lafore, Mathieu Lanusse, Eun-Suk Yang.

\section{References}

${ }^{1}$ Penner, J., "Aviation and the Global Atmosphere," Tech. rep., Intergovernmental Panel on Climate Change, Jan 1999.

2 "IPCC Special Report on Emissions Scenarios," Tech. rep., Intergovernmental Panel on Climate Change, Working Group III, Aug 2000 [cited February 5, 2009].

${ }^{3}$ Sausen, R., Isaksen, I., Grewe, V., and Hauglustaine, D., "Aviation radiative forcing in 2000: An update on IPCC (1999)," METEOROLOGISCHE ZEITSCHRIFT-BERLIN-, Jan 2005.

4 "Strategic Research Agenda 1," Agenda, Advisory Council for Aeronautics Research in Europe, Oct 2002 [cited February $5,2009]$.

5 "Strategic Research Agenda 2," Agenda, Advisory Council for Aeronautics Research in Europe, Nov 2004 [cited February $5,2009]$.

6 "2008 Addendum to the Strategic Research Agenda," Tech. rep., Advisory Council for Aeronautics Research in Europe, Sep 2008 [cited February 5, 2009].

7 "2008-2012 FAA Flight Plan: Charting the Path for the Next Generation," Electronic, Washington, DC, 2008.

8 "Obama energy plan," Obama for America Campaign, Oct 2007 [cited November 3, 2008].

9 "California's Motor Vehicle Global Warming Regulations," [online]. 2007 [cited February 5, 2009].

10 "Improved Fuel Economy Standards - Global Warming," [online]. 2007 [cited February 5, 2009].

${ }^{11}$ Fletcher, B. B., "Center for Biological Diversity v. NHTSA," Legal Opinion 06-71891, United States Court of Appeals for the Ninth Circuit, San Francisco, CA, November 15, 2007 [cited February 5, 2009].

${ }^{12}$ Broder, J. M., "Obama Directs Regulators to Tighten Auto Rules," New York Times, January 26, 2009 [cited February $5,2009]$.

${ }^{13}$ 111th Congress 2009-2010, "H.R. 2454: American Clean Energy and Security Act of 2009," June 2009

${ }^{14}$ Collier, F., "ERA/SFW System Level Metrics," .

15 "Integrated Noise Model," Federal Aviation Administraiton, 2006 [cited 26 April 2007].

${ }^{16}$ Nuic, A., "User Manual for the Base of Aircraft Data (BADA) Revision 3.7," Scientific Report 2009-003, Eurocontrol Experimental Center, Brétigny-sur-Orge, France, March 2009.

${ }^{17}$ Fleming, G. G., "Aviation Environmental Design Tool (AEDT) Overview," Presentation, U. S. Department of Transportation, Volpe Transportations Systems Center, December 2006.

${ }^{18}$ Roof, C., Hansen, A., Fleming, G., Thrasher, T., Nguyen, A., Hall, C., Grandi, F., Kim, B., Usdrowski, S., and Hollingsworth, P., "Aviation Environmental Design Tool (AEDT) System Architecture," Tech. Rep. AEDT-AD-01, USDOT Volpe Center and CSSI Inc. and ATAC Inc. and Wyle Laboratories Inc. and Georgia Tech, Cambridge, MA, January 2007.

${ }^{19}$ Poles, D., "Base of Aircraft Data (BADA) Aircraft Performance Modelling Report," Scientific Report 2009-008, Eurocontrol Experimental Center, Brétigny-sur-Orge, France, March 2009 [cited 8 September 2009].

20 "Procedure for the Calculation of Airplane Noise in the Vicinity of Airports," Standard AIR1845, SAE International, Warrendale, PA, March 1986.

${ }^{21}$ Hollingsworth, P., Pfänder, H., Jimenez, H., Won, H., Lanusse, M., and Lafore, G., "Modeling of Vehicle Environmental Characteristics Including New Technologies/Concepts for the Next Generation Air Transportation System," Presentation at January 2009 NASA Systems Analysis, Design, and Optimization Meeting at AIAA Aerospace Sciences Meeting, 5 January 2009.

${ }^{22}$ Hollingsworth, P., Pfänder, H., Jimenez, H., Won, H., Lanusse, M., and Lafore, G., "Modeling of Vehicle Environmental Characteristics Including New Technologies/Concepts for the Next Generation Air Transportation System," Presentation at NASA Subsonic Fixed Wing Project NRA Annual Review, 23-25 September 2008.

${ }^{23}$ Dubois, D. P. and Paynter, G. C., "“Fuel Flow Method 2" for Esitmating Aircraft Emissions," SAE 2006 Transactions: Journal of Aerospace, Vol. V115, No. 1, 2006, pp. 1-14.

${ }^{24}$ ECAC.CEAC Doc 29: Report on Standard Method of Computing Noise Contours Around Civil Airports, Vol. 1, European Civil Aviation Conference, 3rd ed., December 2005.

${ }^{25}$ ECAC.CEAC Doc 29: Report on Standard Method of Computing Noise Contours Around Civil Airports, Vol. 2, European Civil Aviation Conference, 3rd ed., December 2005.

26 "ICAO Engine Emissions Databank," 07 April 2008 [cited 23 June 2008]. 
27 "ICAO Annex 16 Volume II Aircraft Engine Emissions Ed 3," Policy, International Civil Aviation Organization, Montreal, Canada [cited January 30, 2009].

28 "Research Opportunities in Aeronautics - 2008," Solicitation, National Aeronautics and Space Administration, Washington, DC, Jun 2008

29 "ICAO Annex 16 Volume I Aircraft Noise," Policy, International Civil Aviation Organization, Montreal, Canada [cited January 30, 2009].

${ }^{30}$ Kim, B., Fleming, G., Balasubramanian, S., Malwitz, A., Lee, J., Ruggiero, J., Waitz, I., Klima, K., Stouffer, V., LEong, D., Kostiuk, P., Locke, M., Holsclaw, C., Morales, A., McQueen, E., and Gillette, W., "System for Assessing Aviation's Global Emissions: Version 1.5," Technical Manual FAA-EE-2005-01, Federal Aviation Administraiton, Washington, DC, September 2005.

31 "Model for Assessing Global Exposure to the Noise of Transport Aircraft," [online]. August 2006 [cited 13 June 2008].

${ }^{32}$ Kirby, M. and Mavris, D., "The Environmental Design Space," 26th Internation Congress of the Aeronautical Sciences, Anchorage, AK, September 2008.

${ }^{33}$ Kirby, M. and Mavris, D., "Enhancing the Environmental Policy Making Process," 47th AIAA Aerospace Sciences Meeting including The New Horizons Forum and Aerospace Exposition, Orlando, FL, January 5-8 2009.

${ }^{34}$ Green, J. E., "Climate change - the impact of aviation and the scope for reducing it," UTIAS-MITACS International Workshop on Aviation and Climate Change, Toronto, May 29-30 2008.

${ }^{35}$ M. L. Parry, O. F. Canziani, J. P. Palutikof, P. J. van der Linden, and C. E. Hanson, Eds, Contribution of Working Group II to the Fourth Assessment Report of the Intergovernmental Panel on Climate Change, Cambridge University Press, Cambridge, UK, 2007. 